\title{
Oral health and socio-economic status among children during Syrian crisis: a cross-sectional study
}

\author{
Bahaa Aldin Alhaffar ${ }^{1 *} \mathbb{D}$, Raeed Alawabdi², Leen Barakat ${ }^{3}$ and Chaza Kouchaji ${ }^{4}$
}

\begin{abstract}
Background: The Syrian crisis has started eight years ago and has, directly and indirectly, affected all the aspects of the Syrians lives. A lot of new war-related factors contributed to change the socio-economic status, the demographical distribution and the ability to access the public health services. Moreover, the crisis created the biggest displacement crisis both inside and outside Syria. Therefore, it is important to study the prevalence of dental caries and oral health in these specific circumstances in order to build a database to assess and compare future results of preventive programs and to assess health and social needs of the communities affected by war or crisis. The aim of this research is to Study the level of oral health among children during the Syrian crisis, as well as the relation between oral health and socioeconomic status (SES).
\end{abstract}

Methods: A cross-sectional study to assess the oral health of children in Damascus city by using DMFT index and other dental indices. The data were collected from ten randomly selected schools covering all the areas of Damascus city, and the final sample size was 811 children.

Results: DMFT index was used to assess the oral health of the children. The average number was (3.36) among all children; $14 \%$ of the sample size had a good oral health, while $86 \%$ had at least one decayed, missed, or filled tooth. There was also a strong association between SES of the child and the oral health represented as DMFT Index $(P=0.03)$, Pearson's correlation test displayed an inverse association between the SES and oral health $(P=-0.074)$.

Conclusion: This study highlights the impact of the Syrian crisis on the SES of the Syrian children and their oral health. Bad oral health has been recorded and it has a significant relation with the SES of the children.

Keywords: Oral health, DMFT index, Socioeconomic status, Syrian crisis

\section{Background}

The Syrian crisis began in 2011 and has had serious consequences on Syrians. There are roughly 13 million people currently in need of medical services, and the requirements necessary to helping these people have exceeded the available resources. WHO (World Health Organization) has only received $1 / 3$ of the funding needed to implement the Humanitarian Activities Plan for 2016 [1]. Moreover, as a result of the crisis, many healthcare providers were reported as killed, fled out of the country, or have lost their workplace [2]. The decrease in health and education

\footnotetext{
*Correspondence: Bhaa.alhafar@gmail.com

${ }^{1}$ Faculty of Dentistry, Department of Periodontology, Damascus University,

Alkhateeb sq, Damascus, Syria

Full list of author information is available at the end of the article
}

services have been devastating to the country and its people [3]. Syrian citizens are facing extremely difficult economic conditions, which affecting their capacity to survive by themselves and provide the needed support for their families [4].

Despite the importance of oral health and its effects on general health, oral health has been completely neglected during the Syrian crisis. The relative cost and complexity of dental health services made it very hard for people to access oral health [5]. A research published in 2019 has reported a higher rate of dental caries than expected and the prevalence among children was 79.1\% with an average DMFT of (2.03) [6].

Caries, are the most common chronic disease of oral health diseases, and according to WHO they are the 
main cause of tooth pain and loss for children [7]. Decays are located on the surface of the tooth and It has a clear pathogenesis, the microorganisms cause the tooth minerals to decay, and if left untreated may lead to tooth loss [8]. Dental decays start as a white spot of demineralization and the progression of the white spot to dental decays is determined upon the balance between demineralization and remineralization [9].

Decays are widespread throughout the world; it is a general health problem in several countries [10]. Studies have shown that poor oral health also leads to different systemic diseases such as cardiovascular and respiratory diseases $[11,12]$. The prevalence of tooth decays differs among countries, as it is more prevalent in less developed countries due to poorer socioeconomic status [13], as well as environmental factors [14]. Decays are complex and socioeconomic status is an important risk factor for the occurrence of decays especially in children [15].

There is a direct association between education level and oral health in children. Higher education levels provide a better understanding of oral health and general health [16]. Individuals with a low level of education tend to have a higher prevalence of decays than their counterparts [17], and so as children whose mothers had a high educational level tend to have a better oral health than the children whose mothers had a lower level [18].

Therefore, it is important to study the prevalence of tooth decays and oral health as an indicator for the general health, especially during this period of time in Syria.

\section{Aims of the research}

- Studying the level of oral health among children during the Syrian crisis.

- Studying the implications of the socio-economic status on oral health.

\section{Methods}

Research methodology

A cross-sectional research was carried out to study the prevalence of caries among children and its relation to (SES).

\section{Sampling}

The original sample population includes seventh-grade schoolchildren, most of the registrants are (12) years old. This age is considered very important as it is the age when the child moves from primary school; which means they this is the last age in which a reliable sample can be collected easily through the school system. It is also more likely that most of the permanent teeth (except the third molar) have emerged. Therefore, this age group was chosen to express significant global comparisons and orientations of diseases [19]. The sample size was calculated based on the recorded numbers in the Directorate of Education in Damascus. Simple random sampling technique was used to select the schools from which the sample would be collected to cover all areas of the city. Damascus has a total of (1200) schools, about (145) of them include seventh grade classes. The number of students enrolled in the seventh grade during the academic year (2017-2018) was about (35 thousand) students [20]. The final sample size was (811) children. The median age was (12.5) The number of males was $431(53.1 \%)$ and females 380 (46.9\%). With a 95\% confidence level and a (3.39 \pm ) confidence interval.

\section{School selection criteria}

The schools were selected according to the geographical distribution of the areas in Damascus city. The capital was divided into five areas (Northeast, Northwest, South-East, South-West and Downtown) and Ten schools were randomly selected from the final list which was provided by the ministry of education, this official list contains only the schools which have both the residents students in the area and new students who lost their houses from around Damascus, in order to represent the general population in the sample size, the random selection was made using a simple Excel equation to select two schools from each area in the city.

Moreover, all parts of Damascus city have a similar access to public health services and to governmental hospitals. The government has distributed the internal displaced people across all the parts of Damascus in almost equal numbers and the refuges were mostly residents in temporary residential places created by the government around Damascus. Finally, all parts of the city have the same socioeconomic status and have been affected with the same circumstances during the Syrian crisis.

\section{Student selection criteria}

Each school had a different number of seven-grade classes. Two seven-grade classes were randomly selected, and all students who signed consent form have been examined to collect the oral indices. Because of the war, not all students were of the same age, some were older or younger than the age of the seventh grade, which is normally 12 years old. The reason behind this is directly related to the Ministry of Education's merging process, that aims to give students a chance to continue their education after dropping out schools because of the crisis in Syria.

There was no difference between the displaced students who lost their houses and moved to other areas, and the students who are residents in the host community where the school is located the research question might be sensitive to the students during the time of the data collection. 


\section{Research procedure}

Consent papers have been given to the students on the first day in order to obtain their parents approvals, and data has been collected from the children whom their parents agreed to participate in this study on the second day. All children who didn't show the approval paper have not been included in the study. The socio-economic status questionnaire was distributed and the students' oral examination was done according to WHO guidelines for conducting surveys, which was published in the Oral Health Surveys Basic Methods fifth edition. Data were collected during the period from 11 September to 19 November 2017. All the dentist participated in this study were from Damascus University; seven dentists in total collected the data. One dentist has a master degree in oral medicine and he was responsible for the oral examination which means that all the examinations were carried out by one dentist. Two dentists have a master degree in periodontology and they were responsible for the oral hygiene instructions and to teach the children how to brush their teeth. Moreover, four dentists were fifth-year students during the time of the data collection and they helped to collect the data and handled other organizational duties during the data collection in schools.

The oral examination was done in each school for all the students with signed consent paper, a separated room in the school was allocated and all protective and infection control procedure were taken in consideration.

\section{Materials used}

A special data collection questionnaire is used, and it consist of three sections:

1. Personal Information (Demographic Data): Includes gender, age, current and previous residence, and current grade.

2. Assessment of the Socio-economic status: The evaluation of the socioeconomic status was assessed by five questions. The questions were related to first, - the education of both the father and the mother of the children, second, the monthly family income, and third, profession of father and mother. Based on the previous questions, the SES was divided into 3 categories (high, moderate and low) [21, 22].

3. The number of missing, decayed and filled teeth in children according to DMFT index, gingival index according to Löe-Silence, and plaque and periodontitis index according to Ramfjord.

\section{Examination tools}

Gingival probe (WHO probe), disposable dental explorer, disposable dental mirror, Cotton rollers, Personal protective equipment (PPE).

\section{Ethical approvals}

Ethical approval has been obtained from the Ministry of Higher Education, the School Health Directorate, and the Deanship of the Faculty of Dentistry.

\section{Statistical analysis}

The data was analyzed using SPSS V.22, using descriptive statistics (percentages, means, median, standard deviations) in addition to using inferential statistics using (T-test, ANOVA, Pearson's correlation).

\section{Results}

Data analysis showed a high rate of DMFT among children in Damascus city, the average DMFT was (3.36) and it ranged between $(0-13)$. Fourteen percent of the included sample had good oral health and did not show any decayed, missed, or filled teeth, while the rest (86\%) of the sample had at least on oral health problem.

The average number of decayed teeth was (2.93),it ranged between $(0-12)$ and the caries prevalence in the city was (83\%). Females had a slightly higher rate of the average DMFT value (3.56) compared to males (3.19) (Table 1).

However, T-test didn't show a significant difference between the two variables $(P=0.075)$. Moreover, ANOVA test did not show any significant difference between the oral health represented as DMFT average value and the geographical distribution of the data $(P=0.063)$, which means there is no difference between the sectors of the city in the matter of oral health (Table 2).

The average number of missed teeth was 0.48 and the average number of filled teeth was 0.02 . The average plaque index value was 0.79 and the gingival index value was 0.85 .

According to the level of SES the children divided into three levels, first, children with low SES (44.1\%), second, children with moderate SES (39.6\%), and third children with high SES (16.3\%).

ANOVA test showed a significant association between oral health and the level of (SES) was found $(P=0.03)$, and the average DMFT for the low SES was (5.65), moderate SES (3.85), and for the high SES level (2.43). The correlation between the two variables according to Pearson's correlation is significant and negative $p=-0.074$, the lower the SES gets, the value of DMFT will be increased, which indicates poor oral health. Figure 1 shows the relationship between DMFT index and SES.

\section{Discussion}

Studies over the past decade have shown a remarkable difference in oral health among individuals with higher social and economic status compared to individuals with lower social and economic status [19]. In this study, the assessment of the Socio-economic status was using the family income, father and mother level of education, and 
Table 1 The average value of the DMFT index according to the gender

\begin{tabular}{|c|c|c|c|c|c|}
\hline \multirow{2}{*}{$\begin{array}{l}\text { The average } \\
\text { value }\end{array}$} & \multicolumn{2}{|c|}{ Children who have a decayed, missed or filled teeth } & \multicolumn{2}{|c|}{ Children who do not have a decayed, missed or filled teeth } & \multirow[t]{2}{*}{ variables } \\
\hline & $\%$ & the number & $\%$ & the number & \\
\hline 3.19 & $446 \%$. & 362 & $85 \%$. & 69 & male \\
\hline 3.56 & $414 \%$. & 335 & $55 \%$. & 45 & female \\
\hline- & $86 \%$ & 697 & $14 \%$ & 114 & Total \\
\hline
\end{tabular}

profession of both the father and mother, and in this study, almost half of the sample have a low socio-economic status. While other used many other indicators to assess the social and economic status, one of the most important indicators that can be used is occupation, family income and level of education. Each indicator covers a different aspect of social classes [20]. Income and level of education is a tool frequently used to measure social and economic status, as they are primarily responsible for securing the basic necessities of health. The current income is shown through a direct appreciation of the conditions of life, and health habits and behavior, which also reflects the individual's position and style in society [23].

The difference in income is closely related to mortality and disease incidence, including oral diseases, the low rate of both income and year of the study resulted in an increased in the risk of oral diseases [17]. Previous studies conducted on a number of adults showed that member of the lower class have lower oral health compared to those in the higher class who tend to take constant care of their health [24].

In addition, in a study of the economic and social context of the spread of the need for dental treatment, the need for higher-income individuals to treat was less [25]. And in this research, the result was similar to the previous study, and we found that lower overall oral health can be found in children from low SES.

The low economic and social situation constituted about $50 \%$ of the factors influencing the prevalence of tooth caries and gingivitis at 12 years old. Which is closely linked to health, behavioral change and lifestyle, so they are emphasized in preventive methods [15].

in this research the average DMFT was 3.36 which is considered higher prevalence compared to the WHO recommendations. The prevalence of dental caries among children in low social and economic status schools is associated with oral health behavior and eating habits. The social and economic situation is a high-risk factor for children's teeth [26].

Although the role of parents regarding the oral health and the low level of social services was not statistically significant, there was an indirect relationship between the role of parents in oral health education and eating habits [27].

In a study conducted in India on 12-year-old children, the prevalence and severity of dental caries were low among children in urban areas compared to the less developed. The percentage of boys was greater than that of girls. It was observed that there was no methodology and regularity in oral care procedures and dental clinics are not visited frequently. The presence of dental caries is markedly visible as it is linked to gender, place of residence, frequency of use of brush, frequency of consumption of carbonated beverages and sweets, parenting and education [28].

There is great concern today about the dental health of poorer children deprived of health services as recent data show that these children are more likely to be exposed to dental caries. For example, studies have shown that children living in poor and non-fluorinated communities in the United Kingdom have a lot of caries

Table 2 Statistical tests to study the relationship between SES and the level of oral health

\begin{tabular}{|c|c|c|c|c|c|}
\hline Variable & & Average DMFT & Percentage of the sample & Statistical test & $P$ value \\
\hline \multirow[t]{2}{*}{ gender } & male & 3.19 & $53.1 \%$ & T-test & 0.075 \\
\hline & female & 3.56 & $46.9 \%$ & & \\
\hline \multirow[t]{3}{*}{ Socio-economic status } & Low & 5.65 & $44.1 \%$ & ANOVA Test & 0.03 \\
\hline & Moderate & 3.85 & $39.6 \%$ & & \\
\hline & High & 2.43 & $16.3 \%$ & Pearson's correlation & -0.074 \\
\hline \multirow[t]{5}{*}{ Geographical area } & Northeast & 4.03 & $21.8 \%$ & ANOVA & 0.063 \\
\hline & Northwest & 3.5 & $19.5 \%$ & & \\
\hline & South-East & 3.86 & $21.2 \%$ & & \\
\hline & South- west & 2.89 & $22.5 \%$ & & \\
\hline & Downtown & 2.53 & $15.6 \%$ & & \\
\hline
\end{tabular}




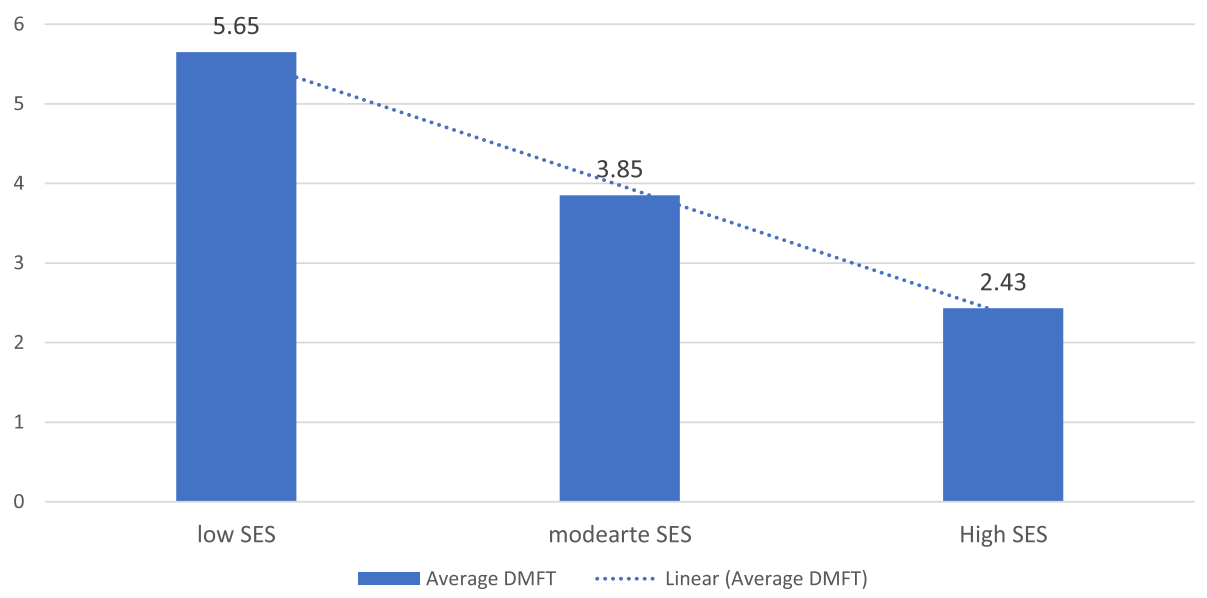

Fig. 1 Relation between (SES) and Average DMFT

compared to those who live in better conditions within the fluorinated communities [29].

A study in Korea in 2008-2010 showed that the number of dental brushing varied depending on socio-economic factors and noted that the persons involved in the research had a higher income and were more interested in brushing their teeth. It also explained that higher-income participants and high-level educational recipients were more interested in using secondary oral care products such as dental floss and intraoral brushes, mouth rinses (chlorhexidine) and electric brushes [30].

WHO has determined that the number of dental caries must not exceed three in children at 12 years, and we have found in our study a value higher than the global value [31]. The previous national survey showed a significant prevalence of caries and poor oral health, with only $6-15 \%$ of the individuals safe from oral diseases such as caries and gingivitis [32].

A large proportion of the 15-year-olds had a high concentration of calculus in Syria [33], which corresponds to our study where we found a high value for calculus.

In the study of H. Kalsbeek and W.H. van Palenstein Helderman for oral health problems in children in Palmyra at $13-15$ years of age, it was found that although oral care had been received, only $27 \%$ of the individuals studied were free of oral health diseases, and $29 \%$ suffered from non-treating painful caries, $24 \%$ suffered from gum bleeding and $24 \%$ suffered from orthotics and cosmetic problems. These numbers correspond to our study where we found that only $14 \%$ of the sample were free of oral disease [34].

Compared to the previous studies results, we find a decline in oral health during the Syrian crisis and an increase in the number of teeth decayed and teeth lost due to dental necrosis.

The average DMFT value in our study was 3.36 , where this value exceeds the DMFT average for the 12-years age group in 1988 in Syria that were estimated as 1.9 and also higher than the 1994 study that has been estimated as 2.5 and more than in 1998 which has been estimated as 2.3 [35].

In comparison to the global average of DMFT 2000 for the same age group, which is estimated as 2.4, we notice that the value in this study is higher than the global average [36].

The study of 2014 in Lattakia in Syria showed that the value of DMFT was estimated as 2.35 for the age group 12 years [37], which is less than our study's value. It may be due to a number of factors. The most important one is that the capital city - Damascus - was affected by a large set of Syrian crisis factors and changes in the economic situation for the population [37].

Regionally, a study was conducted in Eastern Saudi Arabia in 2014 showed the value of DMFT 2.0 for the 10-12 age group, which is less than our study's value [38].

Recent studies have shown a relationship between (SES) and oral health, where the results showed a significant association between educational level and oral health [29].

In a study conducted in Iraq during the 2007 war on 12-years-old school children, dental treatments were significantly more pronounced in children with parents with a higher educational level and in populations with higher socio-economic status [39]. This is also reflected in the Casanova study of school children aged 6-13 years in Mexico, where children with mothers that have a higher educational level tended to care and brush their teeth more than children with a lower mother educational level [18].

Moreover, it has been shown that the type of school and grade reached by the child can affect his/her oral health. Therefore, it appears that a child who has completed a lower educational level may have a lack in oral health knowledge more than a child with a higher 
educational level. In addition, the child's grades significantly affect his/her oral health and the amount of caries he/she has [40]. This coordinates with our current study that verifies the significant relationship between the educational level and oral health among children.

Schools can provide the best rules and basic concepts about oral health care, which helps children at this stage to establish and develop oral health acquisition skills [38].

This research studied the oral health among children during the years of the Syrian crisis, and the prevalence of the decayed, missed, or filled teeth among the sample. Despite the limitations of this research, it can be considered as a reference point for any future compression between the oral health among Syrian sample and the oral health during the time of the crisis. Also, the results of this research showed an association between the oral health and the level of the Socio-economic status among the Syrian children, which can be useful to direct any future governmental or nongovernmental oral health plans or awareness campaign to focus on the most needed areas and children from low socio-economic status.

\section{Suggestions and recommendations}

1) Emphasize on the importance of oral health care for children.

2) Cooperation with schools and institutions that deals with children to provide the best oral health awareness services.

3) Work on the application of fluorinated materials to protect the teeth from necrosis.

4) Adopting a preventive educational program and focusing on the importance of educational attainment for children.

5) Emphasize the role of the parents in education and dissemination the health awareness among their children.

6) Establish a specific formula for cooperation between the University of Damascus, the Ministry of Education (MOE) and the Ministry of Health $(\mathrm{MOH})$ to raise awareness among children.

7) Conducting additional educational studies for the oral health and its relation to the educational attainment level for children.

\section{Limitation}

This research is limited to a certain sample size and certain timeframe, and the study design of this research makes the generalization of the results inappropriate.

\section{Conclusion}

There are high levels of dental caries among children, and higher rate of dental caries can be predicted among children from a lower socioeconomic status, and the
Syrian crisis could have played an important role in decreasing the oral health by changing the socioeconomic status of the people and by make it harder to access for the public health services. However, this study is limited to this sample and can not conclude a causal relation between the socioeconomic status and oral health, and that would need more research with different methodology.

\section{Abbreviations \\ DMFT: Decayed, missed, filled tooth; SES: Socio-economic status}

\section{Acknowledgements}

This research could not be completed without the great efforts of the medical team, which contributed in the collection of data over the period of conducting this research from all Damascus districts. And their names are the following: Khattab Mustafa - Samira Sabbagh - Ghalia Shbib - Kamal Alyabroudi.

\section{Authors' contributions}

BAA: designed the chart, completed the statistical analysis and wrote the results section, helped in writing the introduction, methods, and discussion sections, finalized the paper. RA: wrote the introduction section, helped in writing methods, and discussion sections, helped in finalizing the paper. LB: wrote the introduction section, helped in writing methods, and discussion sections, helped in finalizing the paper. CK: participated as the research supervisor, edited and corrected the research manuscript. All authors approved the final manuscript as submitted and agreed to be accountable for all aspects of the work.

\section{Funding}

The authors confirm the independence of this research completely from any governmental or non-governmental authorities or local /international organizations, and the research is self-funded by the authors.

\section{Availability of data and materials}

All necessary data are presented within the manuscript. All other materials and data are available upon request. For any more details regarding the data of this research please contact the corresponded author - dr. MHD bahaa Aldin Alhaffar

\section{Ethics approval and consent to participate}

The research ethical approval reference number is 669\S - data: 18-04-2017, and it was obtained from the scientific committee at the faculty of dental medicine, the ethical committee at Damascus university, the ministry of education, and from the directory of education in Damascus governate, and the ethical approval is signed and approved by the following personals: 1dean of the faculty of dental medicine - Damascus university prof. dr. Salem Rakkab, 2- Prof. dr. Chaza Koushaji head of the pediatric department, 3Damascus university secretory and signed by prof. dr. Aattef Naddaf head of the scientific committee at Damascus university, 4- director of Damascus education directory, 5- minister of education.

And official approvals from the ministry of education, and the ministry of higher education has been obtained to enter the school and collect data. Also, we obtained approvals from different security and governmental authorities to collect the data because of the war situation in Syria. Parental consent was obtained before including any of the children in the sample. On the first day visiting the school, Parental consent was given to all the children who are accepted according to the inclusion criteria, and the school staff contacted all the children parents to explain the research procedure according to the authors instructions, and on the second day visiting the school, only children with a completed and singed consent paper where included in the sample and examined, and the process repeated in each school.

Consent for publication

Not applicable. 


\section{Competing interests}

The authors declared no potential conflicts of interest with respect to the research, authorship and/or publication of this article.

\section{Author details}

${ }^{1}$ Faculty of Dentistry, Department of Periodontology, Damascus University, Alkhateeb sq, Damascus, Syria. ${ }^{2}$ Faculty of Dentistry, Department of Cosmetic Dentistry, Damascus University, Damascus, Syria. ${ }^{3}$ Faculty of Dentistry, Damascus University, Damascus, Syria. ${ }^{4}$ Faculty of Dentistry, Pediatric Dentistry Department, Damascus University, Damascus, Syria.

Received: 20 October 2018 Accepted: 17 July 2019

Published online: 25 July 2019

\section{References}

1. WHO organization. Information on the health emergency situation in Syria. 2017. (Arabic reference).

2. Saltaji H, Alfakir H. Oral health consequences of the crisis in Syria. Br Dent J. 2015 Jul 24;219(2):49. https://doi.org/10.1038/sj.bdj.2015.586.

3. Kelleher K. Rapid assessment of the impact of the Syrian crisis on socioeconomic situation in north and Bekaa. WIOMSA. 2015 June;24.

4. UNDP development program for crisis in Syria. Jan-july 2014. (Arabic reference).

5. Ivanković A1, Lukić IK, Ivanković Z, Radić A, Vukić I, Simić A. Dental caries in postwar Bosnia and Herzegovina. Community Dent Oral Epidemiol. 2003 Apr;31(2):100-4.

6. Ballouk MA, Dashash M. Caries prevalence and dental health of 8-12 yearold children in Damascus city in Syria during the Syrian crisis; a crosssectional epidemiological oral health survey. BMC Oral Health. 2019;19:16. https://doi.org/10.1186/s12903-019-0713-9.

7. World Health Organization. Standardization of reporting of dental diseases and conditions. 2015 August 21. Available from: http://apps.who.int/iris/ bitstream/10665/38150/1/WHO_TRS_242.pdf.

8. Abhishek M. Comprehensive review of caries assessment systems developed over the last decade. RSBO. 2012;9(3):316-21.

9. Roopa1 K, Pathak1 S, Poornima1 P, Neena1 IE. White spot lesions: A literature review. Journal of Pediatric Dentistry / Jan-Apr 2015 / Vol 3 | Issue 1. https:// doi.org/10.4103/2321-6646.151839.

10. Rebelo MA, Lopes MC, Vieira JM, Parente RC. Dental caries and gingivitis among 15 to 19 year-old students in Manaus, AM, Brazil. Braz Oral Res. 2009; 23:248-54.

11. Linden GJ, Lyons A, Scannapieco FA. Periodontal systemic associations: review of the evidence. J Clin Periodontol. 2013;40(Suppl. 14):S8-19.

12. Jin $\amalg$, Lamster IB, Greenspan JS, Pitts NB, Scully C, Warnakulasuriya S: Global burden of oral diseases: Emerging concepts, management and interplay with systemic. Health. Oral Dis 2015.

13. David J, Wang NJ, Astrøm AN, Kuriakose S. Dental caries and associate factors in 12-year-old schoolchildren in Thiruvananthapuram, Kerala, India. Int J Paediatr Dent. 2005;15:420-8.

14. Vanobbergen J, Martens L, Lesaffre E, Bogaerts K, Declerck D. Assessing caries in the primary dentition. Community Dent Oral Epidemiol. 2001;29: 424-34

15. Hobdell MH, et al. Oral diseases and socio-economic status (SES). Br Dent J. 2003 Jan 25;194(2):91-6.

16. Timis T, Danila. Socioeconomic Status and Oral Health. J Prev Med. 2005;13: $116-21$.

17. Jiang Y, Okoro CA, Oh J, Fuller DL. Sociodemographic and health-related risk factors associated with tooth loss among adults in Rhode Island. Prev Chronic Dis. 2013;10:E45.

18. Casanova-Rosado AJ, Medina-Solís CE, Casanova-Rosado JF, Vallejos-Sánchez AA, Maupomé G, Avila-Burgos L. Dental caries and associated factors in Mexican schoolchildren aged 6-13 years. Acta Odontol Scand. 2005;63:245-51.

19. Oral health U.S. The National Institute of Dental and Cranio-facial Research, USA, 2002.

20. Whittle J, Whittle K. Household income in relation to dental health and dental health behaviours: the use of super profiles. Community Dent Health. 1998;15:150-4.

21. Dak-Albab RJ, Dashash MA. The influence of socioeconomic status on oral health-related quality of life among Syrian children with cleft lip, or palate, or both. Saudi Med J. 2013;34(2):181-6.
22. Clark JD, Mossey PA, Sharp L, Little J. Socioeconomic status and orofacial clefts in Scotland, 1989 to 1998. Cleft Palate Craniofac J. 2003;40:481-5.

23. Healthy people 2010. US Department of Health and Human Services, 2000

24. Astrom AN, Haugejorden O, Skaret E, Trovik TA, Klock KS. Oral impacts on daily performance in Norwegian adults: the influence of age, number of missing teeth, and socio-demographic factors. Eur J Oral Sci. 2006;114: $115-21$

25. Kim DW, Park JC, Rim TT, Jung UW, Kim CS, Donos N, Cha IH, Choi SH. Socioeconomic disparities of peri-odontitis in Koreans based on the KNHANES IV. Oral Dis. 2014;20:551-9.

26. Jones $\mathrm{CM}$, Worthington $\mathrm{H}$. Water fluoridation, poverty and tooth decay in 12-year-old children. Science Direct. 2001.

27. Jerkovic $\mathrm{K}$, et al. Differences in oral health behaviour between children from high and children from low SES schools in the Netherlands. Community Dent Health. 2009 Jun;26(2):110-5.

28. Kumar S, Tadakamadla J, Duraiswamy P, Kulkarni S. Dental caries and its sociobehavioral predictors- an exploratory cross-sectional study. J Clin Pediatr Dent. 2016;40(3):186-92. https:/doi.org/10.17796/1053-4628-40.3.186.

29. Park JB, Han K, Park YG, Ko Y. Association between socioeconomic status and oral health behaviors: the 2008-2010 Korea national health and nutrition examination survey. Exp Ther Med. 2016 Oct;12(4):2657-64.

30. Paula JS, Ambrosano GM, Mialhe FL. The impact of social determinants on schoolchildren's oral health in Brazil. Braz Oral Res. 2015;29:1-9.

31. Aggeryd T. Goals for oral health in the year 2000: cooperation between WHO, FDI and the national dental associations. Int Dent J. 1983;33:55-9.

32. Khattib YA, Serawan MH. National oral health survey. Ministry of Health. Oral Health Department, 1998.

33. Beiruti N, Taifour D, Boles W. Oral health care and periodontal disease among schoolchildren in the Syrian Arab Republic. East Mediterr Health J. 1996:2:304-10.

34. Kalsbeek $\mathrm{H}$, van Palenstein Helderman WH. Oral health in 13-15-year-old schoolchildren in Palmyra, Syrian Arab Republic. Leiden, The Netherland: TNO Prevention and Health; 2004.

35. Beiruti $\mathrm{N}$, van Palenstein Helderman WH. Oral health in Syria. Int Dent J. 2004;54:383-8.

36. Petersen PE. Continuous improvement of oral health in the 21st century the approach of the WHO Global Oral Health Programme, The World Oral Health Report. world health organization; 2003.

37. Salman B, Nour Allah AA, Sultan K. The prevalence of caries among 13-15 children. Tishreen University Journal for Research and Scientific Studies Health Sciences Series Vol. (36) No. (2) 2014.

38. Faroogi FA, Khabeer A, Moheet IA, Khan SQ, Farooq I, ArRejaie AS Prevalence of dental caries in primary and permanent teeth and its relation with tooth brushing habits among schoolchildren in eastern Saudi Arabia. Saudi Med J. 2015 Jun;36(6):737-42. https://doi.org/10.15537/smj.2015.6.10888.

39. Ahmed NA, Astrøm AN, Skaug N, Petersen PE. Dental caries prevalence and riyear-oldrs among 12-year old schoolchildren from Baghdad, Iraq: a postwar survey. Int Dent J. 2007 Feb;57(1):36-44.

40. Kim HY, Kim Y, Hwang JM, Park YD. Oral health behaviors according to demographic characteristics in Korean adolescents: a national representative sample. Int Dent J. 2011;61:168-73.

\section{Publisher's Note}

Springer Nature remains neutral with regard to jurisdictional claims in published maps and institutional affiliations.

Ready to submit your research? Choose BMC and benefit from:

- fast, convenient online submission

- thorough peer review by experienced researchers in your field

- rapid publication on acceptance

- support for research data, including large and complex data types

- gold Open Access which fosters wider collaboration and increased citations

- maximum visibility for your research: over $100 \mathrm{M}$ website views per year

At $\mathrm{BMC}$, research is always in progress.

Learn more biomedcentral.com/submissions 